\title{
Treatment of enterohemorrhagic Escherichia coli (EHEC) infection and hemolytic uremic syndrome (HUS)
}

\author{
Paul N Goldwater ${ }^{1 *}$ and Karl A Bettelheim²
}

\begin{abstract}
Verotoxigenic Escherichia coli (VTEC) are a specialized group of E. coli that can cause severe colonic disease and renal failure. Their pathogenicity derives from virulence factors that enable the bacteria to colonize the colon and deliver extremely powerful toxins known as verotoxins (VT) or Shiga toxins (Stx) to the systemic circulation. The recent devastating $E$. coli 0104:H4 epidemic in Europe has shown how helpless medical professionals are in terms of offering effective therapies. By examining the sources and distribution of these bacteria, and how they cause disease, we will be in a better position to prevent and treat the inevitable future cases of sporadic disease and victims of common source outbreaks. Due to the complexity of pathogenesis, it is likely a multitargeted approach is warranted. Developments in terms of these treatments are discussed.

See related article: http://www.biomedcentral.com/ 1741-7015/10/11
\end{abstract}

Keywords: enterohemorrhagic Escherichia coli (EHEC), verotoxigenic (VTEC) hemolytic uremic syndrome (HUS), treatment, pathogenicity, EAHEC

\section{Introduction}

The association of verotoxigenic Escherichia coli (VTEC) with human disease goes back over 30 years [1-3]. The occurrence of outbreaks due to VTEC in the USA in 1982 [4] focused the world's attention onto these pathogens. Since the discovery of verocytotoxin $[1,3]$, and the paper by Karmali et al. [5] of cases of post-diarrheal

\footnotetext{
* Correspondence: paul.goldwater@health.sa.gov.au

${ }^{1}$ Microbiology and Infectious Diseases, SA Pathology at the Women's and Children's Hospital, and Discipline of Paediatrics, University of Adelaide, 72 King William Road, North Adelaide, South Australia, Australia Full list of author information is available at the end of the article
}

hemolytic uremic syndrome (D+HUS) caused by VTEC, otherwise known as Shiga-toxigenic Escherichia coli (STEC), a large body of knowledge has accumulated, yet despite this information, successful treatment of these infections has remained elusive.

\section{Sources and pathogenesis of VTEC infection Sources and spread of VTEC}

Gut colonization of farm animals, especially ruminants such as cattle, sheep and goats is the likely origin of VTEC/STEC. From these sources derive a variety of vehicles of transmission to humans, including many different foods of animal or plant origin, and water used for swimming and drinking and for growing edible plants. Human fecal contamination of food and seeds could also play a role, especially in developing countries [6].

The potential for VTEC spread is further compounded by globalization of food, which presents a great opportunity for VTEC to spread quickly to large sections of the population. Global food distribution carries an inherent risk and presents great difficulties in controlling foodborne pathogens and in identifying sources of outbreaks, as was recently witnessed in Europe. This is further discussed in the commentary by Werber et al. [7].

\section{VTEC strains}

Various strains of VTEC exist, and, as discussed in the linked commentary, $\mathrm{O} 157$ clones, although less prevalent than non-O157 strains, tend to be more virulent. Thus, although non-O157 VTEC strains had originally been reported and continued to be reported, albeit only by dedicated microbiologists, most researchers in the field largely ignored them. No attention appears to have been given to the generally observed fact that there is a widespread diversity of $E$. coli serotypes in the human intestine at any one time [8] and this has also been found in animals, especially cattle [9]. Most ruminant feces contain a variety of VTEC serotypes, but some, such as $\mathrm{O} 157$ and also O111, though rarely present and
C Biomed Central 
then in only small numbers, are particularly virulent. Importantly, an increasing number of other serotypes can be involved and one study of an outbreak has shown that the more VTEC serotypes with which a patient is infected, the worse the clinical condition [10] (though the main VTEC serotype was O111). While isolations of VTEC O111 from cattle are rare, non-VTEC strains, which are otherwise indistinguishable from the VTEC strains, appear abundant, especially in the feces of sick cattle and patients [11].

Detailed studies [12] have shown that the Shiga toxins can be subdivided into a series of subtypes and that these are also host specific. Thus there is a 'double host specificity' among VTEC strains. Some clones are specific to cattle, while others are specific to sheep. The toxin subtypes these strains carry are specific to the VTEC types found in these mammalian hosts. Therefore, by not looking for the presence of all VTEC serotypes during an outbreak, a great deal of epidemiological information is lost and indication of the source animal is not identified.

\section{Pathogenesis of post-diarrheal hemolytic uremic syndrome} VTEC/STEC/enterohemorrhagic E. coli (EHEC) belong to clones of zoonotic $E$. coli of different $O$ serogroups. These serogroups have evolved and acquired specific virulence factors that enable the bacteria to colonize and infect the human colon, usually without invasion of the blood stream [13]. Once they have been ingested, STEC/VTEC/EHEC cause bloody diarrhea (BD), severe colitis and HUS. These bacteria are known as EHEC when infection is associated with severe colonic and/or renal disease. The production of Vero/Shiga toxins have been considered the basis for their pathogenicity, however, other toxins such as subtilase cytotoxin (SubAB) [14] and cytolethal distending toxin [15] and secreted protease of C1 esterase inhibitor from EHEC (StcE) probably play a role [16].

The recent outbreak of foodborne E. coli O104:H4 in Europe has once again drawn attention to STEC or EHEC infections together with their devastating complications of renal failure (through HUS), and stroke from intravascular coagulopathy and vasculopathy or thrombotic microangiopathy. The unusual virulence and lethality of the O104:H4 strain is the result of genetic admixture of virulence factors, including enteroaggregative properties and multiple antibiotic resistance, and is a lesson in microbial evolution and the genomic plasticity of E. coli [17]. The O104:H4 strain is now known as an enteroaggregative and enterohemorrhagic E. coli (EAHEC).

We have recently observed the combined properties of enteroaggregative ability (providing strong attachment via fimbriae and colonization of the colonic epithelium) with Shiga toxin (Stx) production in the novel and highly lethal European E. coli O104:H4 strain. It has since been shown that this strain belonged to an enteroaggregative $E$. coli lineage that had acquired genes for Shiga toxin 2 and antibiotic resistance [18].

The pathogenesis of HUS disease remains incompletely understood; remarkably, during HUS serum Stx is undetectable. It seems polymorphonuclear leukocytes $(\mathrm{PMN})$ are key players in delivering Stx to critical sites such as the kidneys. The extent of renal damage in children with STEC-associated HUS may relate to the concentration of Stx present on circulating PMN [19]. Paradoxically, patients with high amounts of Stx on PMN showed preserved or slightly impaired renal function (incomplete form of HUS), whereas cases with low amounts of PMN-Stx usually present with acute renal failure. Moreover, high amounts of PMN-Stx induce a reduced release of cytokines by the renal endothelium, with congruent lower degree of inflammation, while low toxin PMN amounts trigger a cytokine cascade, provoking inflammation with consequent tissue damage. The microvasculature plays an important role in pathogenesis: D+HUS is associated with platelet thrombi in the microvasculature of almost all vascular beds [20]. Plasma from HUS patients induces apoptosis of cultured microvascular endothelial cells from most organs [21]. Two key events are involved in the pathogenesis of $\mathrm{D}$ +HUS: altered Von Willebrand factor (VWF) activity (for example, as seen with 'a disintegrin and metalloproteinase with thrombospondin motif-13' (ADAMTS13) deficiency) and site-specific activation and/or apoptosis of microvascular endothelial cells. A deficiency in ADAMTS13, which mediates proteolytic processing of newly released proadhesive ultralarge VWF multimers from endothelial cells, is also thought to play a role in D+HUS coagulopathy [22]. Targeting the interruption of these processes gives hope for potential novel treatment modalities.

Bacterial gut pathogens target the follicle-associated epithelium overlying Peyer's patches. The microorganisms breech the intestinal barrier via $M$ cells and are captured by mucosal macrophages [23]. STEC/EHEC are able to interact in vivo with Peyer's patches and translocate through the mucosa. After being taken up by macrophages and M cells the bacteria produce Stx and induce apoptosis of these host cells and Stx release. These microbe/host cell interactions could represent new therapeutic targets [23].

\section{Current treatment strategies: a multitargeted approach}

HUS comprises acute renal failure and its consequential perturbation of fluid and electrolyte balance, hemolysis, disruption of the clotting cascade with thrombocytopenia, with the risk of stroke. This syndrome, together with the further effects of toxin, and complement complex formation, must be managed and addressed 
urgently using a multitargeted approach. This involves the institution of general supportive measures, antiplatelet and thrombolytic agents and thrombin inhibitors, selective use of antimicrobials, probiotics, toxin neutralizers (synthetic and natural binders, antibodies, and so on); and antibodies against key pathogenetic pathway elements to interrupt pathological processes (for example, inhibition of terminal complement complex formation). Targeting PMNs carrying Stx could be a productive strategy for future research, as could possible gene therapy. The management of D+HUS is complex by virtue of the nature of the condition and the variety of pathways affected. Table 1 summarizes the approach to management and lists trialed and experimental treatments.

\section{General supportive measures}

Fluid levels and electrolyte balance are extremely important in preventing and managing the development of HUS [24,25] (See Table 1).

Acute renal replacement therapy (ARRT); for example, peritoneal dialysis (PD) or hemodialysis) has been shown to improve outcomes. Children with D+HUS and acute kidney injury given early PD may have improved outcomes without risk of bleeding in patients with low platelet counts. Moreover, the procedure seems safe especially in cases with very low platelet counts with no bleeding episodes recorded [26]. Alternatively, hemodialysis is often necessary. Antihypertensive therapy for hypertension when appropriate is also necessary. There seems to be a beneficial role for plasma infusion [27] and plasma exchange [28], however, benefit from apheresis remains uncertain [29].

\section{Managing hematological issues and coagulopathy}

Monitoring of hemoglobin, hematocrit and platelet count is essential. Monitoring hemolysis with lactate dehydrogenase (LDH) and haptoglobin is also helpful. Anemia resulting from hemolysis may need correction with transfusions of whole blood or packed red cells. Platelet transfusion is rarely required and usually avoided $[13,30]$.

\section{Preventing the further effects of toxin Antimicrobials: to use or to avoid?}

Due to the potential for undesirable release of verotoxin (VT)/Stx by dying and dead bacterial cells, antibiotics are usually avoided [31]. In addition, the risk of endotoxin release could add to the patient's already potentially lethal burden. In vitro subinhibitory concentrations of antibiotics may increase production and release of VT/Stx [32] via bacteriophage induction [33]. A mouse [34] and piglet study [35] suggested human trials of fosfomycin were warranted. However, pooled prospective data showed no benefit of antibiotics [36]. Only one fosfomycin trial has been reported [37]. However, fosfomycin data has been questioned [38] (See Table 1). While many doctors in Japan still use antibiotics including fosfomycin in patients with definite or possible enteric STEC infections the prevailing consensus elsewhere indicates antibiotics should be avoided [13]. More recent evidence supports this especially in relation to $\beta$ lactam and other bactericidal antibiotics [39].

\section{Lumenal toxin neutralizers (synthetic and natural binders,} antibodies, and so on)

Strategies using ligand mimics of the receptor for Stx, globotriaosylceramide (Gb3), binding to Stx in the gastrointestinal tract with the intention of preventing the spread of toxin to extraintestinal sites have been proposed. However, in clinical practice the damage has already been done before these ligands could be of benefit. Only one clinical trial has been conducted (alas unsuccessfully) with one agent, Synsorb PK, which bore out this fact [40]. Other agents are listed in Table 1 $[41,42]$.

Intralumenal neutralizers might be effective in reducing systemic uptake of toxin but because the toxin is purportedly not found in serum, studies designed to examine the effect of neutralizers on the toxic effects of polymorphonuclear leukocyte-associated toxin would be a first step.

\section{Antibodies}

Neutralizing Shiga toxin-specific antibodies are potentially useful as therapeutic agents. The toxins are $\mathrm{AB}$ toxins with active and binding elements and are obvious targets for antibody neutralization. Monoclonal antibodies targeting the A subunit epitopes of Stx1 have been shown to be highly protective, when administered to lethally treated animals [43]. Orally administered immunoglobulin has been used therapeutically for a number of gastrointestinal infections (for example, rotavirus; Gastrogard-R) [44]. Patients with diarrhea caused by diarrheagenic E. coli, specifically STEC and E. coliexpressing intimin and HEC-hemolysin were treated by administration of pooled bovine colostrum, rich in antibodies to Shiga toxin and enterohemorrhagic E. colihemolysin, in a placebo-controlled, double-blind study. Symptom resolution and fecal excretion of infecting strains were assessed. No effect of colostrum therapy on the carriage of the pathogens or on complications of the infection could be demonstrated, however, stool frequency was reduced [45]. Antibody to E. coli lipopolysaccharide (LPS) also has the potential of therapeutic use through its blocking effect on adherence of STEC to the human intestinal epithelial (Henle 407) cell line [46]. Likewise, human trials would be needed to show clinical effectiveness.

\section{Other toxin binders/neutralizers}

Most of these agents bind to toxin directly and inhibit the binding to its receptor present on the target cells 
Table 1 Approach to management: summarizing trialed and experimental treatments.

\begin{tabular}{|c|c|c|}
\hline Problem & Treatment & Detail and comments \\
\hline \multirow[t]{2}{*}{$\begin{array}{l}\text { Fluid and electrolyte } \\
\text { imbalance }\end{array}$} & Intravenous fluids & $\begin{array}{l}\text { Fluid balance and attention to the volume and sodium content of } \\
\text { intravenous fluids administered early in the disease have been shown to } \\
\text { reduce the risk of developing oligoanuric HUS after Escherichia coli O157:H7 } \\
\text { infections }\end{array}$ \\
\hline & & $\begin{array}{l}\text { Intravenous fluids within first } 4 \text { days of onset of diarrhea (isotonic } \\
\text { preferable). } \\
\text { The overall oligoanuric rate of the } 50 \text { participants was } 68 \% \text {, but was } 84 \% \\
\text { among those not given intravenous fluids in the first } 4 \text { days of illness. The } \\
\text { relative risk of oligoanuria when fluids were not given in this interval was } \\
1.6(95 \% \mathrm{Cl}, 1.1 \text { to } 2.4 ; P=0.02) \text {. Children with oligoanuric HUS were given } \\
\text { less total intravenous fluid }(r=-0.32 ; P=0.02 \text { ) and sodium ( } r=-0.27 ; P= \\
\text { 0.05) in the first } 4 \text { days of illness than those without oligoanuria. }\end{array}$ \\
\hline
\end{tabular}

\begin{tabular}{llll}
\hline Acute renal failure & Acute renal replacement therapy & Peritoneal dialysis (safe with thrombocytopenia) Hemodialysis & {$[26]$} \\
& & Plasma infusion and plasma exchange & \\
& & Uncertain benefit & {$[28]$} \\
& Apheresis & Where indicated & {$[29]$} \\
& Antihypertensives & Transfusion (packed red cells) & {$[13]$} \\
\hline $\begin{array}{l}\text { Hematological: } \\
\text { hemolytic anemia }\end{array}$ & & \\
\hline
\end{tabular}

Hematological: $\quad$ Platelet transfusion (usually avoided) [13,30]

thrombocytopenia

Preventing further Antibiotics

effects of toxin

Generally to be avoided because of VT/Stx/endotoxin release from dying/

The quinolone ciprofloxacin but not fosfomycin causes Shiga toxinencoding bacteriophage induction and enhanced Stx production from $E$. coli O157:H7 in vitro and in vivo in a mouse model.

Lumenal toxin neutralisers: Synthetic ligand mimics

Modified bacteria decorated with Gb3 or Gb4 Super Twig (Gb3 polymer)

Antibodies: Monoclonal against A subunit

Oral bovine colostrum

LPS antibodies

Receptor blockers and toxin intracellular transport inhibitors

Systemic (intravenous) toxin binders
Fosfomycin showed evidence of better outcomes in a

mouse-model of STEC infection and was recommended for human studies. Similar results were observed in a gnotobiotic piglet model. Pooled prospective data showed no benefit of antibiotics There is only a single study purportedly connecting fosfomycin with a reduced risk of HUS

Fosfomycin benefit in humans remains in doubt. The validity of the study has been questioned on the basis that the meta-analysis mischaracterized fosfomycin as being superior to no antibiotics.

Synsorb K; trial showed no benefit

Not yet trialed

Clinical trials awaited

Protective in lethally-challenged animals

No effect on complications; decreases stool frequency but not STEC carriage Reduces in vitro adherence. No human data. Experimental only.

Ac-PPP-tet blocks intracellular transport of Stx2 from Golgi to endoplasmic reticulum (essential for Stx2 toxicity)

Watanabe-Takahashi et al. reviewed other neutralizers that do not act on receptor binding but disrupt intracellular transport of the toxin, effectively neutralizing the toxin.

Cell-permeable peptide binds to Stx2 and prevents acute kidney injury. Increases survival in juvenile baboon model. TVP $(5 \mathrm{mg} / \mathrm{kg})$ delivered intravenously and simultaneously with toxin or at 6 or $24 \mathrm{~h}$ after toxin with daily $1 \mathrm{mg} / \mathrm{kg}$ supplements up to day 4 prevented acute kidney injury and delayed and reduced blood urea and creatinine levels and increased survival. Delayed administration of the peptide significantly reduced thrombocytopenia, but had no effect on anemia. This cell-permeable agent shows promise in counteracting Stx2 lethality in a baboon model; outcomes of human trials are awaited. 
Blockers of endosome-to-Golgi trafficking of Stx

\author{
Recently it was shown that the metal manganese $\left(\mathrm{Mn}^{2+}\right)$ blocks endosome- $[49]$ \\ to-Golgi trafficking of STx and causes its degradation in lysosomes. Mn2+ \\ targets the cycling Golgi protein GPP130. Direct trafficking of STx from early \\ endosomes to the Golgi, (bypassing late endosomes and lysosomes), is a \\ crucial step that allows STx to avoid degradation. $\mathrm{Mn}^{2+}$, as a small-molecule \\ inhibitor targeting this step therefore offers a cheap therapeutic modality \\ given that mice injected with nontoxic doses of $\mathrm{Mn} 2+$ were completely \\ resistant to a lethal STx challenge.
}

Blockers of bacterial Probiotics and host cell

Harmless recombinant bacteria expressing surface molecules that mimic host cell receptors, deceiving pathogen into attaching to probiotic cell rather than the host cell receptor. Unlikely to benefit symptomatic patients but could be beneficial as prophylactic for family and close contact/exposed persons. Supernatant of cultures of Bifidobacterium longum HY8001 is designed to inhibit the effect of VT/Stx through interference of B subunit of VTs in binding to Gb3.

Terminal complement Eculizumab (intravenous) complex formation

This monoclonal antibody blocks activation of complement and Factor $\mathrm{H}$ binding via alternative pathway.

Promising results in small clinical pilot study. The antibody was given intravenously at 7 day intervals, twice in two patients and four times in a third patient.

Immunoprophylaxis Vaccines

Promising results in animal studies using:

(1) virulence proteins (Stx1/2, intimin, EspA;

peptides;

(2) avirulent ghost cells of EHEC O157:H7;

recombinant proteins. Gu et al. used a live attenuated EIS-producing

Salmonella vaccine in mice model. Vaccination induced significant increases of EspA, intimin and Stx2 specific lgG in serum and secretory lgA in feces as well as antigen-specific $T$ cell proliferation;

(4) recombinant fimbrial proteins have been developed in a quest to protect against the STEC-related entity piglet edema disease. Early results are mixed.

Tir, EspB, EspD, NleA, and EspA were highly immunogenic in vaccinated and [60] naturally infected subjects and represent future candidates for a STEC vaccine;

(5) DNA vaccines: EHEC Stx2 A2 and B subunits confer immunity in a mouse model;

(6) plant-based oral recombinant Stx2 vaccine protects mice.

EHEC = enterohemorrhagic Escherichia coli; EspA/B/D = E. coli secreted protein A/B/D; Gb3 = globotriaosylceramide; Gb4 = globotetraosylceramide; HUS = hemolytic uremic syndrome; LPS = lipopolysaccharide; NleA = non-LEE-encoded effector A; STEC = Shiga-toxigenic Escherichia coli; Stx = Shiga toxin; Tir = translocated intimin receptor; VT = verotoxin.

[47]. Such novel Stx neutralizers offer a new therapeutic modality against STEC/EHEC infections [47] and are detailed in Table 1.

\section{Systemically-applied (intravenous) toxin binders}

A cell-permeable peptide (TVP) that binds to Stx2 was shown to reduce disease severity and rescue juvenile baboons from a lethal Stx2 dose (50 ng/kg) [48].

\section{Blockers of endosome-to-Golgi trafficking of Stx}

Recently it was shown that the metal manganese $\left(\mathrm{Mn}^{2+}\right)$ blocks endosome-to-Golgi trafficking of STx. [49] This offers a possible cheap therapeutic approach. (Table 1). Blockers of bacterial and host cell interaction: probiotics Gut pathogens display surface molecules enabling the organism to bind to host cell receptors. Similarly, bacterial toxins require host cell receptors for binding and cell entry. To block microbe and host cell interaction 'designer' probiotics have been developed. The harmless recombinant bacteria express molecules that mimic host cell receptors (for example, Gb3) on their surface, thereby deceiving the pathogen into attaching to the probiotic rather than the host cell receptor. Probiotic bacteria must survive the tube journey encountering digestive enzymes and other adverse conditions. Trial data is awaited.

A different approach has used the supernatant of cultures of Bifidobacterium longum HY8001, designed to inhibit the effect of VT/Stx through interference of B subunit of VTs in binding to Gb3 [50].

Inhibition of terminal complement complex formation

Based on evidence that Shiga toxin activates complement and binds factor $\mathrm{H}$ and evidence for an active role of complement via the alternative pathway in diarrhea- 
associated hemolytic uremic syndrome [51,52], a few anecdotal reports of successful treatment of severe Stxassociated HUS with the monoclonal antibody eculizumab have been published [53]. Neurologically, the three patients improved dramatically within $24 \mathrm{~h}$ after the first eculizumab infusion. Clinical improvement was associated with rapid normalization of markers of disease activity. These initial results are extremely promising and outcomes from large-scale randomized placebocontrolled trials are optimistically awaited.

\section{Vaccines}

Several vaccine strategies have been used with variable success in a number of animal models. The strategies have involved the use of recombinant virulence proteins such as Stx, intimin and E. coli secreted protein A (EspA) [54] or peptides [55] or fusion proteins of A and B subunits of Stx2 and Stx1 such as Stx2Am-Stx1B [56] or avirulent ghost cells of EHEC O157:H7 [57]. The application of live attenuated bacteria such as Salmonella as a carrier for vaccine proteins against mucosal pathogens including EHEC have obvious advantages [58]. Other approaches are listed in Table 1[59-62].

Antibodies produced in humans with HUS and in rabbits immunized with type III secreted proteins (T3SPs) from four STEC serotypes, and experimentally infected cattle revealed proteins common to several HUS serotypes [60] (Table 1). These were highly immunogenic in vaccinated and naturally infected subjects and represent future candidates for a STEC vaccine (Table 1).

As well as protein-based vaccines, DNA vaccines are a recent development in EHEC prevention, providing encouraging results in a mouse model [61] (Table 1).

The mode of administration (intramuscular, intranasal, oral, intragastric, and so on) for a number of these vaccines not only affects immunogenicity but also protective effect under challenge. Vaccination with a plantbased oral vaccine protected mice against lethal systemic intoxication with Stx2 [62]. This is seen as encouraging. Clearly there is some time to go before human trials are reported but the numerous and frequent outbreaks of EHEC disease constantly remind us of the urgent need to protect the population against these emerging and often devastating zoonoses.

\section{Future directions and conclusions}

There remain significant barriers to successful treatment of HUS given the complexity of the pathogenesis of HUS, which involves perturbation of key homeostatic pathways involving complex biochemical and physiological systems. It is unlikely that targeting a single pathway with a treatment modality will be sufficiently successful; a multitargeted approach would seem necessary. However, given the apparent success of eculizumab, albeit with tiny case numbers, it could offer a promising strategy for treatment. Treatment is designed to prevent the most serious complications of STEC infection (that is, renal failure and central nervous complications, for example, stroke, and shock), which remain far too common. It is clear that a better understanding of the pathogenesis of HUS will lead to additional and possibly better targets for treatment. The discovery that $\mathrm{Mn}^{2+}$ can block endosome-to-Golgi trafficking will no doubt lead to randomised controlled trials in humans. These will be awaited with keen interest. In terms of prevention, we should question the globalization of food distribution with its inherent dangers and its wasteful use of energy resources resulting in a giant carbon footprint.

\section{Abbreviations}

EHEC: enterohemorrhagic Escherichia coli, VTEC: verotoxigenic Escherichia coli; STEC; Shiga-toxigenic Escherichia coli; HUS: hemolytic uremic syndrome; EAHEC: enteroaggregative and enterohemorrhagic E. coli; VT: verotoxin; Stx: Shiga toxin; D+HUS: post-diarrheal hemolytic uremic syndrome; ARRT: Acute renal replacement therapy; PD: peritoneal dialysis;

\section{Author details}

'Microbiology and Infectious Diseases, SA Pathology at the Women's and Children's Hospital, and Discipline of Paediatrics, University of Adelaide, 72 King William Road, North Adelaide, South Australia, Australia. ${ }^{2}$ K.A.B.: Flat 5, Rosedale Lodge, 220 Chase Side, Southgate, London, N14 4PM, UK.

\section{Authors' contributions}

Both authors read and approved the final manuscript.

\section{Authors' information}

PNG and KAB have been involved in STEC/EHEC research for over 30 years. PNG is a senior consultant clinical microbiologist and infectious diseases physician and with his collaborators has used his professional knowledge to further develop an understanding of STEC infection in children. KAB, now retired, introduced PNG to the fascinating field of E. coli microbiology and both have been close colleagues and research collaborators over many productive years.

\section{Competing interests}

The authors declare that they have no competing interests.

Received: 16 August 2011 Accepted: 2 February 2012

Published: 2 February 2012

\section{References}

1. Konowalchuk J, Speirs Jl, Stavric S: Vero response to a cytotoxin of Escherichia coli. Infect Immun 1977, 18:775-779.

2. Wade WG, Thom BT, Evans BT: Cytotoxic enteropathogenic Escherichia coli. Lancet 1979, 2:1235-1236.

3. Wilson MW, Bettelheim KA: Cytotoxic Escherichia coli serotypes. Lancet 1980, 1:201.

4. Riley LW, Remis RS, Helgerson SD, McGee HB, Wells GJ, Herbert RJ, Olcott ES, Johnson LM, Hargrett NT, Blake PA, Cohen ML: Hemorrhagic colitis associated with a rare Escherichia coli serotype. New Engl J Med 1983, 308:681-685.

5. Karmali MA, Steele BT, Petric M, Lim C: Sporadic cases of haemolyticuraemic syndrome associated with faecal cytotoxin and cytotoxinproducing Escherichia coli in stools. Lancet 1983, 1:619-620.

6. Karch H, Mellmann A, Bielaszewska M: Epidemiology and pathogenesis of enterohaemorrhagic Escherichia coli. Berl Munch Tierarztl Wochenschr 2009, 122:417-424.

7. Werber D, Krause G, Frank C, Fruth A, Flieger A, Mielke M, Schaade L, Stark K: Outbreaks of virulent diarrhoeagenic Escherichia coli - are we in control? BMC Medicine 2012, 10:11.

8. Bettelheim KA, Faiers M, Shooter RA: Serotypes of Escherichia coli in normal stools. Lancet 1972, 2:1224-1226. 
9. Bettelheim KA, Kuzevski A, Gilbert RA, Krause DO, McSweeney CS: The diversity of Escherichia coli serotypes and biotypes in cattle faeces. J Appl Microbiol 2005, 98:699-709.

10. Kulkarni H, Goldwater PN, Martin A, Bettelheim KA: Escherichia coli ' $O$ ' group serological responses and clinical correlations in epidemic HUS patients. Comp Immunol Microbiol Infect Dis 2002, 25:249-268.

11. Hornitzky MA, Mercieca K, Bettelheim KA, Djordjevic SP: Bovine feces from animals with gastrointestinal infections are a source of serologically diverse atypical enteropathogenic Escherichia coli and Shiga toxinproducing E. coli strains that commonly possess intimin. Appl Environ Microbiol 2005, 71:3405-3412.

12. Brett KN, Hornitzky MA, Bettelheim KA, Walker K, Djordjevic SP: Bovine non0157 Shiga toxin 2-containing Escherichia coli isolates commonly possess stx2-EDL933 and/or stx2vhb subtypes. J Clin Microbiol 2003, 41:2716-2722.

13. Tarr PI, Gordon CA, Chandler WL: Shiga-toxin-producing Escherichia coli and haemolytic uraemic syndrome. Lancet 2005, 365:1073-1086.

14. Wang H, Paton AW, McColl SR, Paton JC: In vivo leukocyte changes induced by Escherichia coli subtilase cytotoxin. Infect Immun 2011, 79:1671-1679.

15. Janka A, Bielaszewska M, Dobrindt U, Greune L, Schmidt MA, Karch H: Cytolethal distending toxin gene cluster in enterohemorrhagic Escherichia coli 0157:H- and 0157:H7: characterization and evolutionary considerations. Infect Immun 2003, 71:3634-3638.

16. Grys TE, Walters LL, Welch RA: Characterization of the StcE protease activity of Escherichia coli 0157:H7. J Bacteriol 2006, 188:4646-4653.

17. Denamur E: The 2011 Shiga toxin-producing Escherichia coli O104:H4 German outbreak: a lesson in genomic diversity. Clin Microbiol Infect 2011, 17:1124-1125.

18. Rohde H, Qin J, Cui Y, Li D, Loman NJ, Hentschke M, Chen W, Pu F, Peng Y, Li J, Xi F, Li S, Li Y, Zhang Z, Yang X, Zhao M, Wang P, Guan Y, Cen Z, Zhao X, Christner M, Kobbe R, Loos S, Oh J, Yang L, Danchin A, Gao GF, Song $Y$, Li Y, Yang H, et al: Open-source genomic analysis of Shiga-toxinproducing E. coli O104:H4. New Engl J Med 2011, 365:718-724.

19. Brigotti M, Tazzari P, Pier L, Ravanelli E, Carnicelli D, Rocchi L, Arfilli V, Scavia G, Minelli F, Ricci F, Pagliaro P, Ferretti A, Pecoraro C, Paglialonga F, Edefonti A, Procaccino M, Tozzi A, Caprioli A: Clinical relevance of Shiga toxin concentrations in the blood of patients with hemolytic uremic syndrome. Pediatr Infect Dis J 2011, 30:486-490.

20. Ridolfi RL, Bell WR: Thrombotic thrombocytopenic purpura. Report of 25 cases and review of the literature. Medicine (Baltimore) 1981, 60:413-428.

21. Mitra D, Jaffe EA, Weksler B, Hajjar KA, Soderland C, Laurence J: Thrombotic thrombocytopenic purpura and sporadic hemolytic-uremic syndrome plasmas induce apoptosis in restricted lineages of human microvascular endothelial cells. Blood 1997, 89:1224-1234.

22. Motto DG, Chauhan AK, Zhu G, Homeister J, Lamb CB, Desch KC, Zhang W, Tsai H, Wagner DD, Ginsburg D: Shigatoxin triggers thrombotic thrombocytopenic purpura in genetically susceptible ADAMTS13deficient mice. J Clin Invest 2005, 115:2752-2761.

23. Etienne-Mesmin L, Chassaing B, Sauvanet P, Denizot J, Blanquet-Diot S, Darfeuille-Michaud A, Pradel N, Livrelli V: Interactions with M Cells and macrophages as key steps in the pathogenesis of enterohemorragic Escherichia coli Infections. PLOS ONE 2011, 6:e23594.

24. Ake JA, Jelacic S, Ciol MA, Watkins SL, Murray KF, Christie DL, Klein EJ, Tarr PI: Relative nephroprotection during Escherichia coli 0157:H7 infections: association with intravenous volume expansion. Pediatrics 2005, 115:e673-80

25. Hickey CA, Beattie TJ, Cowieson J, Miyashita Y, Strife CF, Frem JC, Peterson JM, Butani L, Jones DP, Havens PL, Patel HP, Wong CS, Andreoli SP, Rothbaum RJ, Beck AM, Tarr PI: Early volume expansion during diarrhea and relative nephroprotection during subsequent hemolytic uremic syndrome. Arch Pediatr Adolesc Med 2011, 165:884-889.

26. Grisaru S, Morgunov MA, Samuel SM, Midgley JP, Wade AW, Tee JB, Hamiwka LA: Acute renal replacement therapy in children with diarrheaassociated hemolytic uremic syndrome: a single center 16 years of experience. Int J Nephrol 2011, 2011:930539.

27. Rizzoni G, Claris-Appaini A, Edefonti A, Facchin P, Franchini F, Gusmano R, Imbasciati E, Pavanello L, Perfumo F, Remuzzi G: Plasma infusion for haemolytic uraemic syndrome in children: Results of a multicenter controlled trial. J Pediatr 1988, 112:284-290.
28. Slavicek J, Puretić Z, Novak M, Sarnavka V, Benjak V, Glavas-Boras S, Thune S: The role of plasma exchange in the treatment of severe forms of hemolytic-uremic syndrome in childhood. Artif Organs 1995, 19:506-510.

29. McLeod BC: Introduction to the third special issue: clinical applications of therapeutic apheresis. J Clin Apheresis 2000, 15:1-5.

30. Allford SL, Hunt BJ, Rose P, Machin SJ, Haemostasis and Thrombosis Task Force, British Committee for Standards in Haematology: Guidelines on the diagnosis and management of the thrombotic microangiopathic haemolytic anaemias. Br J Haematol 2003, 120:556-573.

31. Wong CS, Jelacic S, Habeeb RL, Watkins SL, Tarr PI: The risk of the hemolytic-uremic syndrome after antibiotic treatment of Escherichia coli 0157:H7 infections. N Engl J Med 2000, 342:1930-1936.

32. Grif $K$, Dierich MP, Karch H, Allerberger F: Strain-specific differences in the amount of Shiga toxin released from enterohemorrhagic Escherichia coli 0157 following exposure to subinhibitory concentrations of antimicrobial agents. Eur J Clin Microbiol Infect Dis 1998, 17:761-766.

33. Zhang X, McDaniel AD, Wolf LE, Keusch GT, Waldor MK, Acheson DW: Quinolone antibiotics induce Shiga toxin-encoding bacteriophages, toxin production, and death in mice. J Infect Dis 2000, 181:664-670.

34. Kurioka T, Yunou Y, Harada H, Kita E: Efficacy of antibiotic therapy for infection with Shiga-like toxin-producing Escherichia coli 0157:H7 in mice with protein-calorie malnutrition. Eur J Clin Microbiol Infect Dis 1999, 18:561-571.

35. Zhang Q, Donohue-Rolfe A, Krautz-Peterson G, Sevo M, Parry N, Abeijon C, Tzipori S: Gnotobiotic piglet infection model for evaluating the safe use of antibiotics against Escherichia coli 0157:H7 infection. J Infect Dis 2009, 199:486-493.

36. Safdar N, Said A, Gangnon RE, Maki DG: Risk of haemolytic uremic syndrome after antibiotic treatment of Escherichia coli 0157:H7 enteritis: a meta-analysis. JAMA 2002, 288:996-1001

37. Ikeda K, Ida O, Kimoto K, Takatorige T, Nakanishi N, Tatara K: Effect of early fosfomycin treatment on prevention of haemolytic uremic syndrome accompanying Escherichia coli O157:H7 infection. Clin Nephrol 1999, 52:357-362.

38. lijima K, Kamioka I, Nozu K: Management of diarrhea-associated hemolytic uremic syndrome in children. Clin Exp Nephrol 2008, 12:16-19.

39. Smith KE, Wilker PR, Reiter PL, Hedican EB, Bender JB, Hedberg CW: Antibiotic treatment of Escherichia coli 0157 infection and the risk of hemolytic uremic syndrome, Minnesota. Pediatr Infect Dis J 2012, 31:37-41.

40. Trachtman H, Cnaan A, Christen E, Gibbs K, Zhao S, Acheson DW, Weiss R, Kaskel FJ, Spitzer A, Hirschman GH: Investigators of the HUS-SYNSORB Pk Multicenter Clinical Trial. Effect of an oral Shiga toxin-binding agent on diarrhea-associated hemolytic uremic syndrome in children: a randomized controlled trial. JAMA 2003, 10:1337-1344.

41. Paton AW, Morona R, Paton JC: Neutralization of Shiga toxins Stx1, Stx2c, and Stx2e by recombinant bacteria expressing mimics of globotriose and globotetraose. Infect Immun 2001, 69:1967-1970.

42. Nishikawa K, Matsuoka K, Watanabe M, Igai K, Hino K, Hatano K, Yamada A, Abe N, Terunuma D, Kuzuhara $H$, Natori Y: Identification of the optimal structure required for a Shiga toxin neutralizer with oriented carbohydrates to function in the circulation. J Infect Dis 2005, 191:2097-2105.

43. Islam MS, Stimson WH: Production and characterization of monoclonal antibodies with therapeutic potential against Shiga toxin. J Clin Lab Immunol 1990, 33:11-16.

44. Davidson GP, Whyte PB, Daniels E, Franklin K, Nunan H, McCloud PI, Moore AG, Moore DJ: Passive immunisation of children with bovine colostrum containing antibodies to human rotavirus. Lancet 1989, 2:709-712.

45. Huppertz HI, Rutkowski S, Busch DH, Eisebit R, Lissner R, Karch H: Bovine colostrum ameliorates diarrhea in infection with diarrheagenic Escherichia coli, Shiga toxin-producing E. coli, and E. coli expressing intimin and hemolysin. J Pediatr Gastroenterol Nutr 1999, 29:452-456.

46. Paton AW, Voss E, Manning PA, Paton JC: Antibodies to lipopolysaccharide block adherence of Shiga toxin-producing Escherichia coli to human intestinal epithelial (Henle 407) cells. Microb Pathog 1998, 24:57-63.

47. Watanabe-Takahashi M, Sato T, Dohi T, Noguchi N, Kano F, Murata M, Hamabata T, Natori Y, Nishikawa K: An orally applicable Shiga toxinneutralizer functions in the intestine to inhibit the intracellular transport of the toxin. Infect Immun 2010, 78:177-183. 
48. Stearns-Kurosawa DJ, Collins V, Freeman S, Debord D, Nishikawa K, Oh SY, Leibowitz CS, Kurosawa S: Rescue from lethal Shiga toxin 2-induced renal failure with a cell-permeable peptide. Pediatr Nephrol 2011, 26:2031-2039.

49. Mukhopadhyay S, Linstedt AD: Manganese Blocks Intracellular Trafficking of Shiga Toxin and Protects Against Shiga Toxicosis. Science 2012, 335:332-335.

50. Kim SH, Yang SJ, Koo HC, Bae WK, Kim JY, Park JH, Baek YJ, Park YH: Inhibitory activity of Bifidobacterium longum HY8001 against vero cytotoxin of Escherichia coli 0157:H7. J Food Protect 2001, 64:1667-1673.

51. Orth D, Khan AB, Naim A, Grif K, Brockmeyer J, Karch H, Joannidis M, Clark SJ, Day AJ, Fidanzi S, Stoiber H, Dierich MP, Zimmerhackl LB, Würzner R: Shiga toxin activates complement and binds factor $\mathrm{H}$ : evidence for an active role of complement in hemolytic uremic syndrome. J Immunol 2009, 182:6394-6400.

52. Thurman JM, Marians R, Emlen W, Wood S, Smith C, Akana H, Holers VM, Lesser M, Kline M, Hoffman C, Christen E, Trachtman H: Alternative pathway of complement in children with diarrhea-associated hemolytic uremic syndrome. Clin J Am Soc Nephrol 2009, 4:1920-1924.

53. Lapeyraque AL, Malina M, Fremeaux-Bacchi V, Boppel T, Kirschfink M, Oualha M, Proulx F, Clermont MJ, Le Deist F, Niaudet P, Schaefer F: Eculizumab in severe Shiga-toxin-associated HUS. N Engl J Med 2011, 364:2561-2563.

54. Gu J, Liu Y, Yu S, Wang H, Wang Q, Yi Y, Zhu F, Yu XJ, Zou Q, Mao X: Enterohemorrhagic Escherichia coli trivalent recombinant vaccine containing EspA, intimin and Stx2 induces strong humoral immune response and confers protection in mice. Microbes Infect 2009, 11:835-841.

55. Wan CS, Zhou Y, Yu Y, Peng LJ, Zhao W, Zheng XL: B-cell epitope KT-12 of enterohemorrhagic Escherichia coli 0157:H7: a novel peptide vaccine candidate. Microbiol Immunol 2011, 55:247-253.

56. Cai K, Gao X, Li T, Wang Q, Hou X, Tu W, Xiao L, Tian M, Liu Y, Wang H: Enhanced immunogenicity of a novel Stx2Am-Stx1B fusion protein in a mice model of enterohemorrhagic Escherichia coli 0157:H7 infection. Vaccine 2011, 29:946-952.

57. Cai K, Gao X, Li T, Hou X, Wang Q, Liu H, Xiao L, Tu W, Liu Y, Shi J, Wang H: Intragastric immunization of mice with enterohemorrhagic Escherichia coli 0157:H7 bacterial ghosts reduces mortality and shedding and induces a Th2-type dominated mixed immune response. Can J Microbiol 2010, 56:389-398.

58. Gu J, Ning Y, Wang H, Xiao D, Tang B, Luo P, Cheng Y, Jiang M, Li N, Zou Q, Mao X: Vaccination of attenuated EIS-producing Salmonella induces protective immunity against enterohemorrhagic Escherichia coli in mice. Vaccine 2011, 29:7395-7403.

59. Tiels P, Verdonck F, Coddens A, Goddeeris B, Cox E: The excretion of F18+ E. coli is reduced after oral immunisation of pigs with a FedF and F4 fimbriae conjugate. Vaccine 2008, 26:2154-2163.

60. Asper DJ, Karmali MA, Townsend H, Rogan D, Potter AA: Serological response of Shiga toxin-producing Escherichia coli type iii secreted proteins in sera from vaccinated rabbits, naturally infected cattle, and humans. Clin Vaccine Immunol 2011, 18:1052-1057.

61. Bentancor LV, Bilen M, Brando RJ, Ramos MV, Ferreira LC, Ghiringhelli PD, Palermo MS: A DNA vaccine encoding the enterohemorrhagic Escherichia coli Shiga-like toxin $2 \mathrm{~A} 2$ and B subunits confers protective immunity to Shiga toxin challenge in the murine model. Clin Vaccine Immunol 2009, 16:712-718.

62. Wen SX, Teel LD, Judge NA, O'Brien AD: A plant-based oral vaccine to protect against systemic intoxication by Shiga toxin type 2. Proc Natl Acad Sci USA 2006, 103:7082-7087.

\section{Pre-publication history}

The pre-publication history for this paper can be accessed here: http://www.biomedcentral.com/1741-7015/10/12/prepub

doi:10.1186/1741-7015-10-12

Cite this article as: Goldwater and Bettelheim: Treatment of enterohemorrhagic Escherichia coli (EHEC) infection and hemolytic uremic syndrome (HUS). BMC Medicine 2012 10:12.

\section{Submit your next manuscript to BioMed Central and take full advantage of:}

- Convenient online submission

- Thorough peer review

- No space constraints or color figure charges

- Immediate publication on acceptance

- Inclusion in PubMed, CAS, Scopus and Google Scholar

- Research which is freely available for redistribution

Submit your manuscript at www.biomedcentral.com/submit
Biomed Central 